REFERENCE:

[1] Marchesoni A, De Marco G, Merashli M, McKenna F, Tinazzi I, MarzoOrtega H, McGonagle DG. The problem in differentiation between psoriatic-related polyenthesitis and fibromyalgia. Rheumatology (Oxford). 2018 Jan 1;57(1):32-40.

Disclosure of Interest: None declared

DOI: 10.1136/annrheumdis-2018-eular.2366

THURSDAY, 14 JUNE 2018

Rheumatoid arthritis - biological DMARDs

\section{THU0547 REAL-WORLD EFFECTIVENESS OF EARLY AGGRESSIVE TREATMENT WITH BIOLOGICAL DISEASE-MODIFYING ANTIRHEUMATIC DRUGS FOR THE TREATMENT OF NEWLY DIAGNOSED POLYARTICULAR FORM OF JUVENILE IDIOPATHIC ARTHRITIS}

B. Huang ${ }^{1}$, E.M. Morgan ${ }^{2}$, C. Chen ${ }^{3}$, J. Guo ${ }^{4}$, D.J. Lovell ${ }^{5}$, H.I. Brunner ${ }^{6}$, on behalf of PCATS. ${ }^{1}$ Div. of Biostatistics and Epidemiology, Cincinnati Children's Hospital Medical Center, Cincinnati, $\mathrm{OH} ;{ }^{2}$ Div. of Rheumatology, ${ }^{3}$ Div. of Biostatistics and Epidemiology, Cincinnati Children's Hospital Medical Center, ${ }^{4}$ University of Cincinnati School of Pharmacy; ${ }^{5}$ Div. of Rheumatology, Cinccinnati Children's Hospital Medical Center,${ }^{6}$ Cincinnati Children's Hospital Medical Center, Cincinnati, USA

Background: Limited evidence from randomised clinical trial suggested early aggressive treatment with biological disease modifying antirheumatic drugs (DMARDs) maybe a better treatment strategy in children with polyarticular form of Juvenile idiopathic arthritis(pJIA). ${ }^{1}$ Three consensus treatment plans (CTP) were recommended for treating children with newly onset of $p J I A .{ }^{2}$ The real-world effectiveness is unknown.

Objectives: Evaluate the comparative effectiveness of early combination CTP vs. the step-up CTP, in treating children with newly diagnozed pJIA, utilising electronic health records (EHR) data collected from routine clinical care.

Methods: This inception cohort is derived from data captured in a single institute EHR from January 2009 to July 2017. Eligible patients are 2-16 years of age, newly $(<6 \mathrm{~m})$ diagnosed with pJIA and treated on DMARD. The first clinical encounter initiate DMARDs is identified as the baseline. The primary end point is clinical Juvenile Arthritis Disease Activity Score (cJADAS) 6 months after the treatment.

Results: Out of 1834 pJIA patients captured in EHR, 432 are eligible for the study. Most patients $(362,84 \%)$ initiated DMARD within 6 month of diagnosis: $105(29 \%)$ on early combination and $257(71 \%)$ on step-up plan. Three months following the initial DMARD assigment, $98(93 \%)$ and $244(95 \%)$ remained on the inital early combination and step-up plan respectively, thus are used in this study Patients on early combination had significantly higher cJADAS score at the baseline (15.5 \pm 6.6 vs. $12.5 \pm 5.9$; Student $P$ value $<0.01)$, and higher rate of $R F(18 \%$ vs. $7 \%$, Chisq $p<0.01)$. After 6 months of treatment, their cJADAS scores are more comparable (mean $\pm S D$ of $6.9 \pm 5.4$ in early combination, and $7.1 \pm 6.1$ in step-up; Student T $p=0.7$ ). After statistically adjusting for treatment selection bias, causal inference methods suggest lower cJADAS is expected had the patient been treated on early combination than on the step-up plan, mean and $95 \%$ confidence interval of averaged treatment effect is $2.90(0.89,4.91)$.

Conclusions: The early combination approach improves clinical outcomes at 6 months more effectively than the step-up strategy in children with newly onset pJIA.

\section{REFERENCES:}

[1] Wallace CA, Ringold S, Bohnsack J, Spalding SJ, Brunner HI, Milojevic D, Hendrickson A. Extension Study of Participants from the Trial of Early Aggressive Therapy in Juvenile Idiopathic Arthritis. The Journal of Rheumatology 2014;41(12):2459-2465. https://doi.org/10.3899/jrheum.140347

[2] Ringold S, Weiss PF, Colbert RA, Dewitt EM, Lee T, Onel K, Kimura Y. Childhood arthritis and rheumatology research alliance consensus treatment plans for new-onset polyarticular Juvenile idiopathic arthritis. Arthritis Care and Research 2014;66(7):1063-1072. https://doi.org/10.1002/ acr.22259
Acknowledgements: Funding Support from PCORI, ME-1408-19 894 (PI, Huang)

Disclosure of Interest: None declared

DOI: 10.1136/annrheumdis-2018-eular.3705

THURSDAY, 14 JUNE 2018

\section{Diagnostics and imaging procedures}

\section{THU0548 STANDARDISED PROCEDURES FOR ULTRASOUND IMAGING IN PAEDIATRIC RHEUMATOLOGY: PROGRESS OF EULAR/PRES TASK FORCE}

J. Vojinovic ${ }^{1}$, P. Collado ${ }^{2}$, I. Janta ${ }^{3}$, L. Carmona ${ }^{4}$, C. Malattia ${ }^{5}$, S. Magni-Manzoni ${ }^{6}$, G. Susic ${ }^{7}$, N. Tzaribachev ${ }^{8}$, V. Ravagnani ${ }^{9}$, L. Rossi-Semerano ${ }^{10}$, D. Kljucevsek ${ }^{11}$ S. Lanni ${ }^{5}$ I. Sudoł-Szopinska ${ }^{12}$, D. Windschall ${ }^{13}$, P. Balint ${ }^{14}$ S. Jousse-Joulin ${ }^{15}$ C. Modesto ${ }^{16}$, N. Boutry ${ }^{17}$, A. lagnocco ${ }^{18}$, E. Naredo ${ }^{19} .{ }^{1}$ University of Nis, Faculty of Medicine, Nis, Serbia; ${ }^{2}$ Hospital Universitario Severo Ochoa, Madrid; ${ }^{3}$ Barcelona University, Barcelona; ${ }^{4}$ Institute for Musculoskeletal Health, Madrid, Spain; ${ }^{5}$ IRCCS Istituto G. Gaslini, Genoa; ${ }^{6}$, IRCCS Ospedale Pediatrico Bambino Gesù, Rome, Italy; ${ }^{7}$ Institute for Rheumatology, Belgrade, Serbia; ${ }^{8}$ Pediatric Rheumatology Research Institute, Bad Bramstedt, Germany, ${ }^{9}$ ASST Mantova C. Poma Hospital, Mantova, Italy; ${ }^{10} \mathrm{CHU}$ de Bicêtre, Le Kremlin Bicetre, France; ${ }^{11}$ University Children's Hospital, Ljubljana, Slovenia; ${ }^{12}$ National Institute of Geriatrics, Rheumatology and Rehabilitation, Warshaw, Poland; ${ }^{13}$ Asklepios Hospital Weissenfels, Weissenfels, Germany; ${ }^{14}$ National Institute of Rheumatology and Physiotherapy, Budapest, Hungary; ${ }^{15} \mathrm{CHRU}$ Brest Site Hopital Cavale Blanche, Brest, France; ${ }^{16}$ Hospital Universitari General Vall d'Hebron, Barselona, Spain; ${ }^{17}$ Roger Salengro Hospital, CHU de Lille, Lille, France; ${ }^{18}$ University of Turin, Turin, Italy; ${ }^{19}$ Hospital Universitario Fundación Jiménez Díaz and Autonoma University, Madrid, Spain

Background: Musculoskeletal ultrasound (MSUS) is dependent on sensitivity of the machine used and the skills of the operator. Additional specificities are unique features of the growing skeleton, which include age-related variation of the thick ness of the articular cartilage (due to incomplete ossification) and the presence of physiologically detected vascularisation even in healthy children.

Objectives: EULAR/PReS task force objective was to develop EULAR/PReS Standardised Procedures for Ultrasound Imaging in Paediatric Rheumatology through a consensus process among rheumatologists, paediatric rheumatologists, and radiologists highly experienced in the performance, teaching and research in paediatric MSUS in rheumatic diseases.

Methods: In the first phase we performed a systematic literature review (SLR) on guidelines for MSUS for children endorsed by international societies and articles on how to perform MSUS scanning in children. Based on the SLR results, project conveners formulated a Delphi survey by selecting the items to be included (i.e. musculoskeletal anatomic structures evaluable by US, scanning technique, and their lesions/abnormalities detectable by US at the principal joint areas). The Delphi survey was distributed among a broad panel of experts in MSUS, selected for their high experience in the performance, teaching and research in MSUS in children. Based on the Delphi results the main anatomical structures (for definitions, photo and video recordings) were selected to be analysed in the final phase organised as an exercise on live healthy children models. The meeting involved: 16 project participants (13 paediatric US experts, fellow, as well as, AHP and PARE representatives), 16 healthy children models (representing four different age groups) accompanied by their parents (who had signed informed consent to participate), 4 photo/imaging technicians, 2 expert technicians in US machines. Results: Structures from 8 musculoskeletal areas (i.e. shoulder, elbow, wrist and hand, hip, knee, ankle and foot) in 4 age groups of children were selected. Detailed scanning procedures (i.e. patient position, probe placement, scanning method and bony/other landmarks) were defined. We recorded the reference photo (live and US image) and video (procedure video clip and US video record) of the scanning procedures. As a result, we obtained photo and video image library with a detailed description of the standardised US procedures in children which can be used as EULAR/PReS web-based educational application. Conclusions: This task force has produced a consensus-based comprehensive and practical framework on standardised procedures for MSUS imaging in paediatric rheumatology.

Disclosure of Interest: None declared

DOI: 10.1136/annrheumdis-2018-eular.3775 
THURSDAY, 14 JUNE 2018

\section{Paediatric rheumatology}

\section{THU0549 ABSENCE OF ASSOCIATION BETWEEN DRUG EXPOSURE AND INFECTION IN PATIENTS WITH POLYARTICULAR-COURSE JUVENILE IDIOPATHIC ARTHRITIS AND INADEQUATE RESPONSE TO BIOLOGIC OR NON-BIOLOGIC DMARDS TREATED WITH SC AND IV ABATACEPT}

N. Ruperto ${ }^{1}$, H. Brunner ${ }^{2}$, N. Tzaribachev ${ }^{1}$, I. Louw ${ }^{1}$, I. Calvo ${ }^{1}$, G. Horneff ${ }^{1}$, M. Henrickson ${ }^{2}$, M.E. Rama ${ }^{1}$, M. Fischbach ${ }^{1}$, T. Miraval ${ }^{1}$, M.M. Ally ${ }^{1}$, X. Li ${ }^{3}$, R. Wong ${ }^{3}$, M. Nys ${ }^{4}$, B. Murthy ${ }^{3}$, K. Lin ${ }^{5}$, J.A. Passarell ${ }^{5}$, A. Martini ${ }^{1}$, D.J. Lovell ${ }^{2}$, on behalf of the PRINTO and PRCSG working groups. ${ }^{1}$ PRINTO, Istituto Gaslini, Genoa, Italy: ${ }^{2}$ PRCSG, CHMC Cincinnati, Cincinnat; ${ }^{3}$ Bristol-Myers Squibb, Princeton, USA; ${ }^{4}$ Bristol-Myers Squibb, Braine-L'Alleud, Belgium; ${ }^{5}$ Cognigen Corporation, a SimulationsPlus Company, Buffalo, USA

Background: Infections are the most common expected AEs linked to biologic (b) DMARDs in paediatric patients (pts) with juvenile idiopathic arthritis (JIA) Blood concentrations achieved with bDMARDs vary greatly between individual pts. It is not known if higher abatacept (ABA) exposure is linked to higher infection risk in paediatric populations.

Objectives: To assess the relationship between the incidence of infection and SC (50-125 mg weekly) and IV (10 mg/kg monthly) ABA exposure in pts with polyarticular-course JIA (pJIA).

Methods: Data from the 4 month open-label periods of a Phase III SC ABA study (NCT01844518; weight-tiered ABA: $\quad 10-<25 \mathrm{~kg} \quad[50 \mathrm{mg}], \quad 25-<50 \mathrm{~kg}$ [87.5 mg], $\geq 50 \mathrm{~kg}$ [125 mg]; 219 pts aged $2-17$ years) and an IV ABA study (NCT00095173; ABA $10 \mathrm{mg} / \mathrm{kg}$ monthly; 184 pts aged 6-17 years) in pts with pJIA were analysed. The association between serum ABA exposure measures (steady-state trough $\left[\mathrm{C}_{\text {minss }}\right]$, maximum $\left[\mathrm{C}_{\text {maxss }}\right]$ and time-averaged $\left[\mathrm{C}_{\text {avgss }}\right]$ concentrations) estimated by population pharmacokinetic analysis and time to first infection (regardless of seriousness) was assessed. Kaplan-Meier (KM) plots of infection probability versus time to first infection by ABA exposure quartiles were created and log-rank test was performed to test the differences in distribution of time to first infection across exposure quartiles. Box plots of $A B A$ exposure measures over time to Month 4 were generated, stratified by first infection occurrence (yes/no). Data for SC and IV ABA were assessed separately and pooled.

Results: Baseline demographic and clinical characteristics were comparable in the SC and IV studies. ${ }^{1}{ }^{2}$ Overall, $135 / 403$ pts (33.5\%) had $>1$ infection over 4 months: $77 / 219(35.2 \%)$ with SC ABA and 58/184 (31.5\%) with IV ABA. KM plots for pooled $S C$ and IV ABA showed no statistically significant difference in infection probability across four quartiles of $A B A C_{\text {minss }}$ (Fig $A ; p=0.2317$; log-rank test), $\mathrm{C}_{\text {maxss }}(\mathrm{p}=0.5501)$ or $\mathrm{C}_{\text {avgss }}(\mathrm{p}=0.3808)$. Consistent results were seen for individually studied SC and IV ABA $C_{\text {minss }}$ (Fig B, C), $C_{\text {maxss }}$ and $C_{\text {avgss }}$ (not shown). In addition, there was no difference in median $A B A$ exposure measures by infection occurrence (yes/no) in pooled and separate SC and IV analyses.
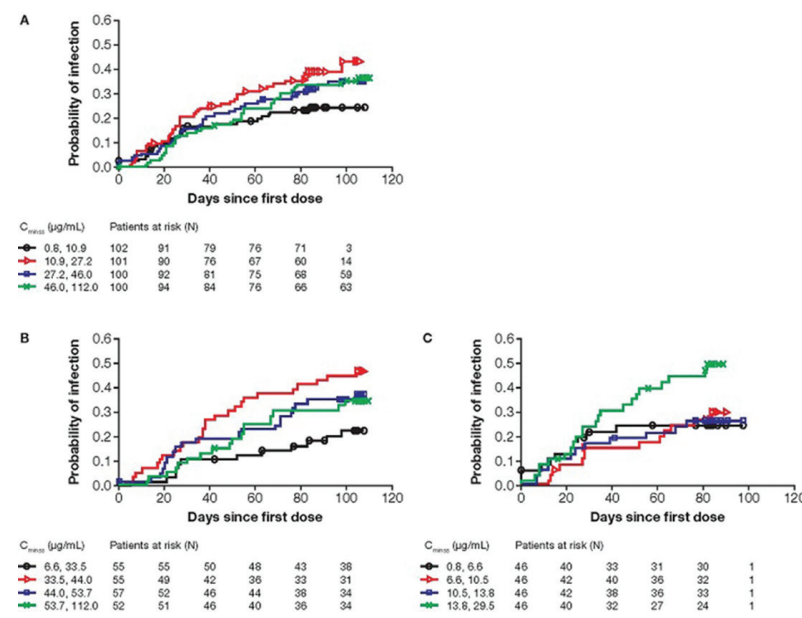

Abstract THU0549 - Figure 1. Kaplan-Meier Plots of Probability of First Infection, Regardless of Seriousness, Versus Days From First Dose to Infection by Abatacept $\mathrm{C}_{\text {minss }}$ Quartiles and Route of Administration: Pooled SC and IV (A); SC (B); IV (C)

Conclusions: In pts with pJIA who received SC or IV abatacept, higher relative abatacept exposure was not associated with a higher risk of infections for 4 months.
REFERENCES:

[1] Ruperto N, et al. Lancet 2008;372:383-91.

[2] Lovell D, et al. Arthritis Rheumatol 2016;68(Suppl 10), abstract 948.

Disclosure of Interest: N. Ruperto Grant/research support from: Bristol-Myers Squibb, Roche, Janssen, Novartis, Pfizer, Sobi, Consultant for: AbbVie, Ablynx, Amgen, AstraZeneca, Baxalta Biosimilars, Biogen Idec, Boehringer Ingelheim, Bristol-Myers Squibb, Celgene, Eli-Lilly, EMD Serono, Gilead Sciences, Janssen, Medlmmune, Novartis, Pfizer, R-Pharm, Roche, Sanofi, Servier, Takeda, Speakers bureau: AbbVie, Ablynx, Amgen, AstraZeneca, Baxalta Biosimilars, Biogen Idec, Boehringer Ingelheim, Bristol-Myers Squibb, Celgene, Eli-Lilly, EMD Serono, Gilead Sciences, Janssen, Medlmmune, Novartis, Pfizer, R-Pharm, Roche, Sanofi, Servier, Takeda, H. Brunner Consultant for: Novartis, Genentech, Pfizer, UCB, Lilly, Janssen, Ablynx, AbbVie, Bristol-Myers Squibb, EMD Serono, AstraZeneca, Speakers bureau: Genentech, Novartis, N. Tzaribachev: None declared, I. Louw Consultant for: Janssen, Pfizer, Roche, I. Calvo Grant/research support from: Novartis, Speakers bureau: AbbVie, Novartis, Roche, Sobi, G. Hor neff Grant/research support from: AbbVie, Bristol-Myers Squibb, Chugai, Pfizer, Janssen/MSD, Novartis, Roche, Consultant for: AbbVie, Bristol-Myers Squibb, Chugai, Pfizer, Janssen/MSD, Novartis, Roche, M. Henrickson: None declared, M. Rama: None declared, M. Fischbach: None declared, T. Miraval: None declared, M. Ally: None declared, X. Li Shareholder of: Bristol-Myers Squibb, Employee of: Bristol-Myers Squibb, R. Wong Shareholder of: Bristol-Myers Squibb, Employee of: Bristol-Myers Squibb, M. Nys Shareholder of: Bristol-Myers Squibb, Employee of: Bristol-Myers Squibb, B. Murthy Shareholder of: BristolMyers Squibb, Employee of: Bristol-Myers Squibb, K. Lin Employee of: Cognigen Corporation, a SimulationsPlus company, J. Passarell Employee of: Cognigen Corporation, a SimulationsPlus company, A. Martini Consultant for: AbbVie, Biogen, Boehringer-Ingelheim, Bristol-Myers Squibb, EMD Serono, Janssen, Novartis, Pfizer, R-Pharm, D. Lovell Grant/research support from: National Institutes of Health, NIAMS, Consultant for: AstraZeneca, Bristol-Myers Squibb, AbbVie Pfizer, Roche, Novartis, UCB, Forest Research Institute, Horizon, Johnson and Johnson, Biogen, Takeda, Genentech, GlaxoSmithKline, Boehringer Ingelheim, Celgene, Janssen, Speakers bureau: Genentech

DOI: 10.1136/annrheumdis-2018-eular.1990

\section{THU0550 NEW IL10 RECEPTOR GENE MUTATION ASSOCIATED TO A SPECTRUM OF INFLAMMATORY APHTHOSIS AND CROHN'S DISEASE}

R. Dagher ${ }^{1}$, V. Modica ${ }^{1}$, N. El Rifai ${ }^{2}$, E. Chouery ${ }^{3}$, M.C. Fadous Khalife ${ }^{1}$. ${ }^{1}$ pediatrics, Notre Dame De Secours University Hospital, Byblos; ${ }^{2}$ pediatrics, Makassed General Hospital; ${ }^{3}$ medical genetics, Saint Joseph University, Beirut, Lebanon

Background: IL-10 is defined as an anti-inflammatory cytokine. Its activity is mediated by interaction with a cell surface receptor composed of 2 subunits: alfa (IL-10RA) and beta (IL-10RB). Homozygozous mutations of IL-10RA gene have been linked to Very Early Onset Inflammatory Bowel Disease (VEO-IBD) in children with a total of 28 mutations identified till present.

Objectives: We report a Lebanese family presenting with a new exonic mutation in the IL-10RA gene variably associated to inflammatory aphthosis and adult onset IBD.

Methods: The proband is a boy born to consanguineous parents who presented to our attention at the age of 9 . He suffered from persistent severe oral aphthosis, recurrent fever and intermittent diarrhoea since the age of 2 months, and anal aphthosis since the age of 7 .

His Familial history is notable for moderate oral aphthosis in the father and adult onset Crohn's disease in a paternal uncle.

He was diagnosed with Behçet disease and received colchicine since the age of 8 with no efficiency.

His physical exam was normal except for severe oral and anal ulcers. No history of genital ulcers.

Laboratory tests revealed normal inflammatory markers. ANA titers, anti-DNA and anti-ENA were negative with normal complement level. Pathergy test and HLA B51 were negative as well as pANCA and cANCA. Iron, Zinc, vitamin and immune deficiencies were ruled out.

Yearly ophthalmologic screening revealed no signs of inflammation.

Repeated gastroscopy and colonoscopy and enteric MRI showed no pathologic findings.

Results: A genomic sequencing study for recurrent fever was performed. A nove heterozygous exonic mutation of the IL-10RA gene (c.G172A G>A, p.E58K) was identified. The child's father and his uncle were found to have the same mutation at homozygous state, however with different phenotypic presentations.

The child was started on Infliximab with favourable outcome after 3 months. Conclusions: In this Lebanese family, the previously unreported IL-10RA gene mutation (c.G172A G $>$ A, p.E58K) is associated to a variable spectrum from 